\title{
Factors Associated with Underweight among Under-Five Children in Eastern Nepal: Community-Based Cross-sectional Study
}

\author{
Deepak Adhikari't, Resham Bahadur Khatri ${ }^{2 *+}$, Yuba Raj Paudel ${ }^{3+}$ and \\ Amod Kumar Poudyal ${ }^{4}$ \\ ${ }^{1}$ Ministry of Health and Population, Kathmandu, Nepal, ${ }^{2}$ Faculty of Medicine, School of Public Health, The University of \\ Queensland, Brisbane, QLD, Australia, ${ }^{3} \mathrm{Nepal}$ Health Sector Support Program, Ministry of Health and Population, \\ Kathmandu, Nepal, ${ }^{4}$ Department of Community Medicine and Public Health, Institute of Medicine, Tribhuvan University, \\ Kathmandu, Nepal
}

OPEN ACCESS

Edited by:

Yoram Chaiter,

Israel Defense Forces

Medical Corps, Israel

Reviewed by:

Daniel Rossignol,

Rossignol Medical Center,

United States

Nirali Chakraborty,

Population Services International,

United States

*Correspondence:

Resham Bahadur Khatri

rkchettri@gmail.com

tThese authors have contributed equally for this work.

Specialty section: This article was submitted to Child Health and Human Development,

a section of the journal

Frontiers in Public Health

Received: 03 October 2017 Accepted: 08 December 2017 Published: 22 December 2017

Citation:

Adhikari D, Khatri RB, Paudel YR and Poudyal AK (2017) Factors Associated with Underweight among Under-Five Children in Eastern Nepal: Community-Based Cross-sectional Study.

Front. Public Health 5:350. doi: 10.3389/fpubh.2017.00350
Background: Undernutrition is a leading cause of morbidity and mortality in children in developing countries including Nepal. This study aimed to identify sociodemographic, environmental, and maternal and child health $(\mathrm{MCH})$ factors associated with objectively assessed underweight among children aged under 5 years in llam district of eastern Nepal.

Methods: A community-based cross-sectional study of 300 mothers of children under 5 years was conducted using interviewer-administered questionnaires from July to August 2012. The sample was derived by randomly selecting three village development committees (VDCs), then three wards from each of these three VDCs were selected making a total sample of nine wards. Finally, individuals were selected from the nine wards using systematic random sampling. Chi-square tests were used to identify factors associated with childhood underweight. Logistic regression analyses were conducted to determine odds ratios for the factors associated with underweight.

Results: The prevalence of underweight was 37\% [95\% confidence interval $(\mathrm{Cl})$ : 33-43\%]. Children who were more than 24 months of age were more likely to be underweight (adjusted odds ratio $(\mathrm{aOR})=2.72 ; 95 \% \mathrm{Cl}: 1.57,4.70)$ than children aged less than 24 months. Children of families who consumed water without treatment had higher odds of being underweight $(\mathrm{aOR}=2.48 ; 95 \% \mathrm{Cl}: 1.28,4.78)$ than those who used water after boiling. Children whose mother perceived their size at birth as normal were more likely to be normal weight $(\mathrm{aOR}=0.40 ; 95 \% \mathrm{Cl}$ : 0.16, 0.99) compared to a smaller size at birth. Children whose growth was monitored had a low chance of being underweight $(\mathrm{aOR}=0.35,95 \% \mathrm{Cl}: 0.15,0.97)$.

Conclusion: Nearly two-fifth of under-five children were found to be underweight. The age of children, drinking water purification practices, growth monitoring, and mother's perception of size at birth were significantly associated with childhood underweight. These findings suggest that interventions focusing on access to child growth monitoring, and water and sanitation practices may reduce the childhood underweight.

Keywords: environmental factors, maternal factors, Nepal, underweight, under-five children 


\section{INTRODUCTION}

Maternal and child undernutrition causes more than $10 \%$ of the total global burden of disease and more than one-third of child deaths $(1,2)$. The poor nutritional status of children and mothers has long-term health consequences, and the ramifications extend to inter-generational low productivity and perpetuation of poverty (3-6). Despite growing emphasis on promotion of maternal and child nutrition through various policies, plans, and programs $(5,7)$, Nepal has not made significant progress in the reduction of maternal and child undernutrition as expected $(8,9)$. For example, stunting in under-five children declined from $57 \%$ in 2001 to $36 \%$ in 2016, and underweight in under-five children declined from $43 \%$ in 2001 to $27 \%$ in 2016 (9). Global literature has revealed that $45 \%$ of under-five deaths are contributed by undernutrition as malnourished children are highly susceptible to childhood diseases (10). Therefore, reduction of underweight can be an important step toward reducing childhood morbidity and mortality in Nepal.

Multiple factors affect childhood nutritional and development status, including household socioeconomic position, child feeding practices, environmental factors, access to and use of health services, and household level hygiene practices (2). Childhood illnesses such as diarrhea and acute respiratory infections, which are associated with poor hygiene and access to sanitation, are common causes of under-nutrition in developing countries including Nepal (11-14). It has been suggested that nutritional interventions and environmental sanitation strategies such as access to clean water, waste disposal, and use of clean household fuels can reduce childhood underweight and reduce child mortality by $14-31 \%$ in developing countries in South Asia and Africa (15).

While there has been some research on the effect of feeding practices and socioeconomic conditions $(14,16-18)$ on childhood undernutrition in Nepal, there is little empirical research on how socioeconomic and environmental conditions may influence childhood underweight. Furthermore, understanding these relationships in rural settings may offer evidence for designing contextual promotion activities. Thus, this paper investigates the association between social, environmental, and maternal and child health $(\mathrm{MCH})$ factors and low weight for age (weight for age $Z$ score $<-2 \mathrm{SD}$ ) among children under 5 years old from a rural district of eastern Nepal.

\section{MATERIALS AND METHODS}

\section{Study Setting}

This cross-sectional study was conducted in Ilam district of eastern Nepal from July to August 2012. Ilam district is one of 75 districts and lies to the east of the country. People from indigenous ethnicities (Rai, Limbu, Rajbansi) represent more than two-third of the population (70\%) in the district. About $72 \%$ females are literate in Ilam, which is one of the highest ranked districts of Nepal regarding the United Nation's Human Development Index $(19,20)$. The agricultural activities especially tea and livestock farming are the major sources of income of people living in Illam district. It has three electoral constituencies and 48 village development committees (VDCs) - the latter being the smallest administrative units in Nepal (20). Each VDC is further divided into nine wards for service delivery and development purposes.

\section{Sampling and Sample Size}

Three VDCs, namely Chulachuli, Godak, and Chamaita, were randomly selected from the list of 48 VDCs, representing each of the three electoral constituencies. Three wards from each participating VDC were then randomly selected resulting in a total sample of 9 wards. Secretaries (administrative in-charge of VDC) and health post in-charges from the selected VDCs were briefed on the research, and they provided their consent to be involved. In Nepal, vitamin A and polio immunization services are provided routinely as well as biannually as national campaigns. The coverage of those services is almost universal among under-five children. Therefore, a sampling frame of children aged under 5 years was prepared from the selected wards by using the vitamin $\mathrm{A}$ and polio immunization register of female community health volunteers (FCHVs) from each ward. This resulted in a sampling frame of 910 households from nine wards of three VDCs. The sample size of 300 was determined based upon an alpha of 0.05 , $29 \%$ prevalence of underweight as per Nepal Demographic and Health Survey (NDHS) 2011, and non-response rate of $10 \%$ using the Epi-Info Stat Calc version 7. The number of participating households per ward ranged from 19 to 54. Systematic sampling (every fourth household) was used for interview and anthropometric measurement.

Mothers of children aged under 5 years were selected for an interview, and the research team undertook anthropometric measurement of the children. If the mother of a child aged under 5 years was not available in the selected households, the adjoining household was recruited, and second visits were undertaken if such household did not have an under-five child. Only five such households which have no under-five children were found during the data collection. If there was more than one eligible child in the same family, the elder child was selected for weight-for-age measurement. If it was not possible to interview the mother in the first visit, a second visit was made to interview the mother. All mothers approached responded to the interviews.

\section{Study Variables and Measurement}

The outcome variable was objectively assessed underweight of children aged under 5 years. Underweight was categorized using the World Health Organization growth chart for children and was defined as being $<-2$ SD from the median reference weight for age (21). Explanatory variables such as sociodemographic factors were mainly self-reported by the child's mother during the interview. However, environmental factors such as the availability of latrines and cooking fuel were observed by interviewers on the day of the interview. Behavior and practicerelated variables were assessed through 24-h recalls of selected mothers. The major explanatory and outcome variables are shown in Table 1.

\section{Data Collection Tools and Techniques}

Three field assistants from each VDC were recruited to assist with data collection. The first author provided a 2-day orientation to 
TABLE 1 | Definition of outcome and explanatory variables.

\begin{tabular}{lll}
\hline SN & Variables & Categories of variables \\
\hline Outcome variable & \\
\hline $1 \quad$ Nutrition status of children & Underweight; normal \\
\hline Explanatory variables & \\
\hline Sociodemographic factors & \\
$2 \quad$ Ethnicity & Disadvantaged (Dalit and Muslim); \\
& & relatively advantaged (non-Dalit and \\
& & advantaged Hill castes Janajatis and \\
3 & Sex of child & upper caste group) \\
4 & Child age & Male; female \\
5 & Birth interval of children & $0-23$ months; $24-59$ months \\
& & None (first child); below 36 months; \\
6 & Maternal age & 36 months or above \\
7 & Household size & ( 20 years; less than 20 years \\
8 & Occupation & $<5$ members; above five members \\
10 & Maternal education & Agriculture; business; labor work \\
11 & Area of land owned & Iliterate; primary education (1-8 grade) \\
12 & Food sufficiency around the year & Yes; no \\
\hline
\end{tabular}

\section{Environmental factors}

13 Source of drinking water

14 Water purified in last $24 \mathrm{~h}$

15 Types of toilet

16 Types of cooking fuel

17 Soap used in previous $24 \mathrm{~h}$

before interview

18 Number of sleeping rooms

\section{Maternal and child health factors}

19 Perceived size at birth

20 Weighted at birth

21 Antenatal check up

22 Place of delivery

23 Postnatal checkup

24 Growth monitoring in previous six Yes; no months before interview

25 Child diarrhea in the last 30 days Yes; no the field assistants on interviewing, data recording, and anthropometric measurement (weight of the children). The intervieweradministered questionnaire was conducted with the mothers of children aged under 5 years. The questionnaire was based on relevant literature and the previous surveys such as the NDHS $(8,18,22)$. The questionnaire was pretested with ten mothers in the adjoining VDC; some minor changes were made in the language according to the local context. Each field assistant checked data for completion and consistencies after each interview, and the researcher later checked the completed questionnaires at the end of the day.

The weight of a child was measured using a standardized calibrated Salter 235-6S Hanging scale, which can measure up to $0.1 \mathrm{~kg}$. The child's weight was taken without shoes and with light clothes. The weight of children aged less than 6 months was taken by infant weighing scale (infant spring scale) that is used in community-based newborn care program in Nepal (23).

\section{Data Entry and Analysis}

Data were entered in Epi-data (The EpiData Association, Odense, Denmark) (24), and analyses were conducted using Statistical Package for Social Sciences (SPSS) version 19 (Armonk, NY, USA: IBM Corp.) (25). Descriptive analyses were conducted including proportions of childhood underweight.

To determine the factors associated with underweight, a twostep modeling approach was undertaken. First, univariate logistic regression analyses of each explanatory variable and underweight were conducted to identify the associations. Second, those variables with $p$-values $<0.1$ were included in a multivariate logistic regression analysis to determine the effect adjusted for each of the other potential explanatory variables. Multicollinearity was assessed through analysis of the correlation coefficients in the correlation matrix. A $p$-value of $<0.05$ denoted statistical significance in the final model.

\section{Ethics Approval and Consent to Participate}

Ethical approval from the Institutional Review Board (IRB) of the Institute of Medicine, Tribhuvan University, was obtained for this study. Before collection of the data, permission from the District Health Office, Ilam was obtained. Health workers from each VDC as well as FCHVs from each ward were briefed on the purpose of the study. This study used verbal informed consent with prior approval from the IRB to include the illiterate mothers. Further, it was explained that mothers could terminate the interview at any time. Before starting the interview, the IRB-approved verbal informed consent form was read by the research assistant, and mothers were asked to agree to participate in an interview and anthropometric measurement of their children. Those who agreed had their names, and the name of their child, recorded in the respondents' summary sheet. After completing this procedure, the interview commenced, and the weight of the child was taken.

\section{RESULTS}

The prevalence of underweight in the study population was $37 \%$ [95\% confidence interval (CI): 33-43\%] (table is not shown).

\section{Sociodemographic Characteristics of the Sample}

The sociodemographic features of the study population are presented in Table 2. Nearly, three quarters of the children (71\%) were from the disadvantaged ethnic groups. Sixty percent of the participating children were male, and just over half (51\%) were less than 23 months of age. Forty-nine percent of children were the first child. Among the 152 children who had a sibling, $28 \%$ had children birth interval of more than 36 months. More than half $(54 \%)$ of the mothers had given birth to their first child before they were 20 years old. Two-third (66\%) of the study population had $\leq 5$ household members, and $21 \%$ of responding mothers were illiterate.

In univariate analyses, three sociodemographic variables; the age of the child, mother's education, and area of land owned were associated with the child being underweight. 
TABLE 2 | Sociodemographic factors and underweight status of children aged under five years in llam district Nepal.

\begin{tabular}{|c|c|c|c|c|}
\hline Sociodemographic factors & Categories & Total number $(\%)^{\mathrm{a}}$ & Underweight children (\%) & $p$-Value $\#$ \\
\hline Ethnicity of mothers & $\begin{array}{l}\text { Disadvantaged group } \\
\text { Relatively advantaged group }\end{array}$ & $\begin{array}{r}212(70.6) \\
88(29.4)\end{array}$ & $\begin{array}{l}81(38.2) \\
31(35.2)\end{array}$ & 0.62 \\
\hline Sex of the child & $\begin{array}{l}\text { Male } \\
\text { Female }\end{array}$ & $\begin{array}{l}181(60.3) \\
119(39.7)\end{array}$ & $\begin{array}{l}73(40.3) \\
39(32.8)\end{array}$ & 0.18 \\
\hline Age group of children & $\begin{array}{l}\text { 0-23 months } \\
24-59 \text { months }\end{array}$ & $\begin{array}{l}154(51.3) \\
146(48.7)\end{array}$ & $\begin{array}{r}44(28.6) \\
68(46.6)\end{array}$ & $<0.001^{*}$ \\
\hline Birth interval of index child & $\begin{array}{l}\text { None (first child) } \\
\text { 12-36 months } \\
\geq 36 \text { months }\end{array}$ & $\begin{array}{r}148(49.3) \\
69(23.0) \\
83(27.7)\end{array}$ & $\begin{array}{l}53(35.8) \\
23(33.3) \\
36(43.4)\end{array}$ & 0.38 \\
\hline Mother's age at first child birth & $\begin{array}{l}\geq 20 \text { years } \\
<20 \text { years }\end{array}$ & $\begin{array}{l}138(46.0) \\
162(54.0)\end{array}$ & $\begin{array}{l}50(36.2) \\
62(38.3)\end{array}$ & 0.71 \\
\hline Household size & $\begin{array}{l}\leq 5 \\
>5\end{array}$ & $\begin{array}{l}197(65.7) \\
103(34.3)\end{array}$ & $\begin{array}{l}76(38.6) \\
36(35.0)\end{array}$ & 0.61 \\
\hline Main maternal occupation & $\begin{array}{l}\text { Agriculture } \\
\text { Business } \\
\text { Labor }\end{array}$ & $\begin{array}{c}247(82.3) \\
23(7.7) \\
30(10)\end{array}$ & $\begin{aligned} 89 & (36) \\
8 & (34.8) \\
15 & (50)\end{aligned}$ & 0.31 \\
\hline Maternal education & $\begin{array}{l}\text { Illiterate } \\
\text { Primary education } \\
\text { Secondary education }\end{array}$ & $\begin{array}{r}62(20.7) \\
41(13.7) \\
197(65.6)\end{array}$ & $\begin{array}{l}31(50.0) \\
20(48.8) \\
61(31.0)\end{array}$ & $<0.001^{*}$ \\
\hline Area of land owned & $\begin{array}{l}\text { Landless } \\
\text { Up to } 0.5 \text { ha } \\
\geq 0.5 \text { ha }\end{array}$ & $\begin{array}{r}30(10.0) \\
167(55.7) \\
103(34.3)\end{array}$ & $\begin{array}{l}19(63.3) \\
61(36.5) \\
32(31.1)\end{array}$ & $<0.007^{\star}$ \\
\hline Food sufficiency around the year & $\begin{array}{l}\text { No } \\
\text { Yes }\end{array}$ & $\begin{array}{l}115(39.0) \\
185(61.0)\end{array}$ & $\begin{array}{l}38(49.3) \\
74(40.0)\end{array}$ & 0.22 \\
\hline
\end{tabular}

${ }^{a}$ Column percentage.

${ }^{b}$ Row percentage.

"Chi-square test of association.

${ }^{*} p<0.05$.

\section{Environmental and $\mathrm{MCH}$ Factors}

Household environmental condition and $\mathrm{MCH}$ factors are presented in Table 3. Ninety-one percent of the households had improved sources of water, and $42 \%$ of families had consumed water without household-level treatment within the $24 \mathrm{~h}$ preceding the survey. About $80 \%$ of the households used solid fuel for cooking. Ninety-six percent of households had a latrine. The use of soap during hand washing was practised in $94 \%$ of the surveyed households.

Ninety-four percent of mothers had received antenatal care services during their last pregnancy. More than half (55\%) of the responding mothers had given birth at a health facility. During the 6 months before the interviews, nine out of 10 children had their weight monitored. About a quarter of the children had experienced diarrhea in the 30 days prior to the survey.

Five environmental factors (household water purification practices, types of the latrine, types of cooking fuel, handwashing with soap and water in the previous $24 \mathrm{~h}$, and the number of sleeping rooms in the house) were associated with underweight among children aged under 5 years (Tables 2 and 3). Similarly, six MCH-related factors were associated with underweight, including place of childbirth (or delivery), antenatal care visits, post-natal care visits, perceived size at birth, weighing at birth, and growth monitoring practices in the last 6 months (Tables 2 and 3).

The multivariate model is shown in Table 4. After checking for multicollinearity, it was found that weighing at birth and place of childbirth were highly correlated (correlation coefficient $=0.92$ ), therefore, weighing at birth was not included in the multivariate model. Out of 13 explanatory variables, only four were significantly associated with childhood underweight. Age group of the child was associated with underweight, with children aged more than 24 months more likely to be underweight $(\mathrm{aOR}=2.72$; 95\% CI: 1.57, 4.70; $p<0.00$ ) than children aged $0-23$ months. Children of families who consumed water without treatment had higher odds of being underweight ( $\mathrm{aOR}=2.48$; $95 \% \mathrm{CI}$ : 1.28 , $4.78 ; p=0.005)$ than those who consumed boiled water. Mother's perception of the size of her child at birth was associated with underweight. Children perceived to be of normal size at birth were less likely to be underweight compared to the children perceived to be small at birth $(\mathrm{aOR}=0.40 ; 95 \% \mathrm{CI}$ : 0.16, 0.99; $p=0.048$ ). Likewise, children who were growth monitored had lower odds of being underweight than those who were not growth monitored $(\mathrm{aOR}=0.35,95 \%$ CI: $0.15,0.97 ; p=0.024)$.

\section{DISCUSSION}

The prevalence of underweight (weight for age $<-2$ SD) was found to be $37 \%$ (95\% CI: $32-43$ ) in the current study. This is higher than the national average (27\%) and that of the eastern region of Nepal (24\%) (9). More than two-thirds of our sample were from the disadvantaged ethnic communities. Those communities usually have low socioeconomic status, lower land ownership, high rates of childbirth at home, and childhood illnesses, which might be accounted for the prevalence 
TABLE 3 | Environmental, maternal and child health $(\mathrm{MCH})$ factors and underweight status of children aged under 5 years in llam district Nepal.

\begin{tabular}{|c|c|c|c|c|}
\hline Environmental factors & Categories & Total number $(\%)^{\mathrm{a}}$ & Underweight children $(\%)^{\mathrm{b}}$ & $p$-Value $\#$ \\
\hline Main source of drinking water & $\begin{array}{l}\text { Improved source } \\
\text { Not improved source }\end{array}$ & $\begin{array}{c}273(91.0) \\
27(9.0)\end{array}$ & $\begin{array}{r}100(36.6) \\
12(57.1)\end{array}$ & 0.41 \\
\hline Water purified in past $24 \mathrm{~h}$ & $\begin{array}{l}\text { Boiling } \\
\text { Filtration } \\
\text { No treatment }\end{array}$ & $\begin{array}{r}143(47.7) \\
30(10.0) \\
127(42.3)\end{array}$ & $\begin{array}{r}49(34.3) \\
6(20.0) \\
57(44.9)\end{array}$ & $0.07^{\star}$ \\
\hline Types of toilet & $\begin{array}{l}\text { Flush latrine } \\
\text { Pit latrine } \\
\text { No latrine }\end{array}$ & $\begin{array}{c}146(48.7) \\
141(47.0) \\
13(4.3)\end{array}$ & $\begin{array}{r}41(28.1) \\
63(44.7) \\
8(61.5)\end{array}$ & $<0.001^{*}$ \\
\hline Type of cooking fuel used & $\begin{array}{l}\text { Solid fuel } \\
\text { Liquid fuel }\end{array}$ & $\begin{array}{r}238(79.3) \\
62(20.7)\end{array}$ & $\begin{array}{l}95(39.9) \\
17(27.4)\end{array}$ & $0.07^{\star}$ \\
\hline Hand washed with soap and water in previous $24 \mathrm{~h}$ & $\begin{array}{l}\text { No } \\
\text { Yes }\end{array}$ & $\begin{array}{c}19(6.3) \\
281(93.7)\end{array}$ & $\begin{array}{r}11(58.0) \\
101(35.0)\end{array}$ & $0.06^{*}$ \\
\hline Number of sleeping rooms & $\begin{array}{l}<2 \text { rooms } \\
\geq 2 \text { rooms }\end{array}$ & $\begin{array}{r}59(19.7) \\
241(80.3)\end{array}$ & $\begin{array}{l}34(57.6) \\
78(32.4)\end{array}$ & $<0.00^{\star}$ \\
\hline \multicolumn{5}{|l|}{ Maternal and child health factors } \\
\hline Perceived size at birth & $\begin{array}{l}\text { Small } \\
\text { Normal }\end{array}$ & $\begin{array}{r}30(10) \\
270(90)\end{array}$ & $\begin{array}{l}18(60.0) \\
94(34.8)\end{array}$ & $<0.001^{*}$ \\
\hline Weighed at birth & $\begin{array}{l}\text { No } \\
\text { Yes }\end{array}$ & $\begin{array}{l}132(44) \\
168(56)\end{array}$ & $\begin{array}{l}59(44.7) \\
53(31.5)\end{array}$ & $0.02^{\star}$ \\
\hline Antenatal care & $\begin{array}{l}\text { No } \\
1-3 \text { visits } \\
4 \text { more visits }\end{array}$ & $\begin{array}{c}19(6.3) \\
90(30.0) \\
191(63.7)\end{array}$ & $\begin{array}{l}13(68.4) \\
41(45.6) \\
58(30.3)\end{array}$ & 0.07 \\
\hline Place of delivery & $\begin{array}{l}\text { Home } \\
\text { Health facility }\end{array}$ & $\begin{array}{l}135(45) \\
165(55)\end{array}$ & $\begin{array}{l}60(44.6) \\
52(31.5)\end{array}$ & $0.022^{*}$ \\
\hline Postnatal care & $\begin{array}{l}\text { No } \\
\text { Yes }\end{array}$ & $\begin{array}{l}121(40.3) \\
179(59.7)\end{array}$ & $\begin{array}{l}54(44.6) \\
58(32.4)\end{array}$ & $0.032^{*}$ \\
\hline Child growth monitoring in past six months & $\begin{array}{l}\text { No } \\
\text { Yes }\end{array}$ & $\begin{array}{r}35(11.7) \\
265(88.3)\end{array}$ & $\begin{array}{l}21(60.0) \\
91(34.3)\end{array}$ & $<0.01^{*}$ \\
\hline Diarrhea in past 30 days before interview & $\begin{array}{l}\text { No } \\
\text { Yes }\end{array}$ & $\begin{array}{r}224(75.0) \\
76(25.0)\end{array}$ & $\begin{array}{l}81(36) \\
31(41)\end{array}$ & 0.49 \\
\hline
\end{tabular}

${ }^{a}$ Column percentage.

${ }^{b}$ Row percentage.

"Chi-square test of association.

${ }^{*} p<0.05$.

of underweight of children aged under 5 years $(26,27)$. Pooled figures of three consecutive NDHS data showed higher odds of early initiation of breastfeeding among mothers with primary education (aOR: 1.24) and secondary or higher education (aOR: 1.63) (27). In our study, about one-third of mothers were either illiterate or only had primary level education, and nearly half of their children were underweight. Lower maternal education has been shown to be associated with late initiation of breastfeeding after birth (27) and poor complementary feeding practices of children aged under 2 years, consequently affecting childhood nutritional status $(28,29)$. Furthermore, mothers who belong to the disadvantaged ethnic groups face food insufficiency around the year and are more likely to engage in labor works for subsistence in Nepal (30). Because of various household chores, mothers from such ethnic groups have less time for child feeding, child caring, and health-seeking during an illness in comparison to the advantaged, educated and wealthy mothers. This consequently affects dietary frequency and diversity in infants and young children $(26,29)$. Contextspecific health information education and communication (IEC)/behavior change communication (BCC) materials such as radio jingle, posters, pamphlets, and other pictorials can be designed in the local languages and delivered through multiple channels so that message can be reached out to disadvantaged communities.

In the current study, children aged 24-59 months were more likely to be underweight than children aged $0-23$ months. A survey carried out in Lao PDR found that children in higher age groups had higher odds of underweight, which is consistent with the current study finding $(31,32)$. Poor socioeconomic status and housing conditions in our study may have contributed to the high prevalence of underweight among children aged 24 months or above. In the rural Nepali contexts, mothers usually give less attention to their children when they reach 2 years of age. At that point, elder siblings or other members of the family take over as their caregivers, which might lead to poor feeding and hygiene practices. As a result, such children are more susceptible to childhood illness, ultimately become underweight (33). Furthermore, nearly one-third of children between the age of 6 and 9 months (30\%) do not receive complementary foods in addition to breastfeeding (12). Such practices are more prevalent among poor and marginalized families, which might also be contributing to children being underweight. This finding suggests that later age within under 5 years' age carry a higher risk of underweight. They 
TABLE 4 | Factors associated with underweight among children aged under 5 years in llam district Nepal.

\begin{tabular}{|c|c|c|c|c|}
\hline Characteristics & $\begin{array}{l}\text { Unadjusted odds ratio (OR) } \\
\text { [95\% confidence interval (CI)] }\end{array}$ & $p$-Value & Adjusted OR (95\% Cl) & $p$-Value \\
\hline Age group of children in months (ref. 0-23 months) & & $<0.001$ & & $<0.00^{\star}$ \\
\hline $24-59$ & $2.18(1.35,3.51)$ & & $2.72(1.57,4.70)$ & \\
\hline Maternal education (ref. illiterate) & & $<0.001$ & & 0.19 \\
\hline Primary education & $0.69(0.37,1.28)$ & & $0.82(0.40,1.67)$ & \\
\hline Secondary education & $0.36(0.19,0.69)$ & & $0.59(0.26,1.33)$ & \\
\hline Area of land owned (ref. landless) & & $<0.007$ & & 0.18 \\
\hline Up to 0.5 ha & $0.33(0.17,0.75)$ & & $0.38(0.15,1.008)$ & \\
\hline$\geq 0.5$ ha & $0.26(0.11,0.61)$ & & $0.39(0.15,1.08$ & \\
\hline Water purified in past $24 \mathrm{~h}$ (ref. boiling) & & $<0.07$ & & $0.005^{\star}$ \\
\hline Filtration & $0.48(0.18,1.25)$ & & $0.93(0.32,2.69)$ & \\
\hline No treatment & $1.56(0.95,2.55)$ & & $2.48(1.28,4.78)$ & \\
\hline Types of toilet (ref. no latrine) & & $<0.001$ & & 0.20 \\
\hline Pit latrine & $0.50(0.16,1.61)$ & & $1.55(0.34,6.98)$ & \\
\hline Flush latrine & $0.24(0.07,0.79)$ & & $0.97(0.20,4.55)$ & \\
\hline Type of cooking fuel used (ref. liquid fuel) & & 0.07 & & 0.446 \\
\hline Solid fuel & $1.75(0.95,3.25)$ & & $1.36(0.61,3.05)$ & \\
\hline Soap used during hand washing in past $24 \mathrm{~h}$ (ref. no) & & 0.06 & & 0.237 \\
\hline Yes & $0.40(0.16,1.04)$ & & $0.48(0.14,1.61)$ & \\
\hline Number of sleeping room (ref. <2 rooms) & & $<0.000$ & & 0.59 \\
\hline$\geq 2$ rooms & $0.35(0.19,0.63)$ & & $1.17(0.64,2.15)$ & \\
\hline Perceived size at birth (ref. small) & & $<0.001$ & & $0.048^{*}$ \\
\hline Normal & $0.35(0.16,0.77)$ & & $0.40(0.16,0.99)$ & \\
\hline Antenatal care (ref. no) & & $<0.000$ & & 0.09 \\
\hline $1-3$ times & $0.38(0.13,1.10)$ & & $0.54(0.14,2.03)$ & \\
\hline 4 or more & $0.20(0.07,0.55)$ & & $0.36(0.09,1.39)$ & \\
\hline Place of delivery (ref. home) & & 0.022 & & 0.41 \\
\hline Health facility & $0.57(0.35,0.92)$ & & $1.40(0.61,3.19)$ & \\
\hline \multicolumn{5}{|l|}{ Postnatal care (ref. no) } \\
\hline Yes & $0.59(0.37,0.95)$ & 0.032 & $0.89(0.40,1.99)$ & 0.79 \\
\hline Child growth monitored in past 6 months (ref. no) & & 0.004 & & $0.024^{*}$ \\
\hline Yes & $0.35(0.17,0.72)$ & & $0.35(0.15,0.97)$ & \\
\hline
\end{tabular}

${ }^{*} p<0.05$, significance in multivariate analysis.

Ref., reference.

need more attention, especially in the frequent feeding of diversified foodstuff in adequate quantity during pre-school period of the children, and the practice should be promoted.

In this study, children from families who consumed water without any treatment, such as boiling, or filtration were found to be more underweight. Poor hygiene and sanitation practices are primarily responsible for childhood illnesses worldwide (34). In this study, about $25 \%$ of children had suffered from diarrhea 1 month prior to the data collection. The higher number of diarrheal cases is reported during the summer season in the district where our study was carried out. Moreover, mothers must do their household chores, in addition to being involved in agricultural activities and labor work for subsistence. This also contributes to poor child caring and such children are more prone to undernutrition (35). Moreover, poor child caring practices increases susceptibility to childhood illnesses such as diarrhea and worm infestations which also leads to underweight (36).

In the current study, the likelihood of being underweight was higher among those children whose mother perceived smaller size at birth than average-a finding consistent with a study conducted in 2014 in Nepal (37). Mothers' nutritional status determines the nutrition of their children at birth (38). In Nepal, about half of the pregnant women are anemic or have low body mass index (12). A randomized controlled trial conducted in Nepal reported that the supplementation of multiple micronutrients during pregnancy increased the birth weight and reduced low birth by $14 \%$ (39). However, there is a widespread cultural belief that if a pregnant woman consumes a lot of nutritious food during her pregnancy, the baby growing in her womb will become very big in size which will then make childbirth more painful and difficult (40). Such belief subjects mothers to nutritional deficiency during pregnancy which might result in intrauterine growth retardation, preterm births, and/or children being born with small size at births. If parents perceive that their newborn is smaller than average or is born with low birth weight, such babies need additional postnatal care and frequent feedings because such children face higher chance of becoming ill $(39,41)$. So, maternal nutrition education and counseling session during antenatal care visits should be promoted focusing on undernourished pregnant women. Parents of low birth weight, preterm, and small babies also need to be made aware of the future implications. The need for adequate attention and nutritional support, caring, and health seeking of such children should also be highlighted.

The children who were not growth-monitored in the last 6 months preceding the survey were over two times more likely 
to be underweight than those who were monitored. Studies have shown that regular growth monitoring is associated with better feeding practices of children $(18,42)$. A review of growth monitoring and promotion impact conducted in 2008 reported that growth monitoring could provide an entry point for preventive and curative health care and were an integral part of programs that were associated with significant reductions in malnutrition (43). Further, it provides an opportunity to promote and encourage breastfeeding and appropriate complementary feeding which results in good nutrition status of children (43). In Nepal, apart from health facilities, growth monitoring sessions are conducted in at least three to five places within the community at the primary health care/primary outreach clinics (PHC/ ORC) on a monthly basis. The national nutrition program has recommended that all children need to be growth-monitored at least six times in the first year, four times in the second year, and three times each in remaining three years (44). Such intervention increases the access to child health services to mothers who live in hard-to-reach areas from the health facilities. Growth monitoring is the entry point which determines children's nutritional status and conducts counseling to the parents/caretakers for improved nutritional knowledge, attitude, and household level practices.

The findings from the current study have several implications for policy, research, and practice. Comprehensive interventions which focus on educating future mothers, improving $\mathrm{MCH}$ service utilization, and improving the economic status of households are required to improve the nutritional situation of children under 5 years of age. Improved feeding practices of preschool children should be promoted. An earlier study suggested enhancing complementary feeding practice in Nepal by focusing on women from poorer households and those less exposed to media for the better nutritional status of children (29). Strategies to improve the nutritional status of children include improving women's educational status (25) and promoting regular growth monitoring practices. These provide an opportunity for counseling mothers about their children's nutritional needs and feeding practices. Furthermore, long-term strategies for improvement of economic status such as homestead food production, kitchen garden, and income-generating activities may also improve the child caring and feeding practices, which can impact nutritional status of children. Similarly, adequate health seeking practices during pregnancy may reduce the chance of low birth weight or preterm babies and if babies are born smaller than average size, more postnatal care, and extra care for such babies may minimize the possibility of being underweight in later months. Because of the high density of indigenous people living in the district (20), there might be many cultural and linguistic barriers to implementation of targeted interventions. More importantly, cultural practices such as eating less during pregnancy, poor food diversity need to be addressed by targeting pregnant women, families, and communities in behavior change communication activities (45). Mass media mobilization, distribution of IEC/ BCC materials as per local context, counseling through peer mobilization (46), or involvement of mother-in-law in prenatal care (47) could be potential strategies to reduce such contextual barriers.

Some limitations of the present study should be acknowledged. A study conducted in eastern Nepal may not be generalizable to communities from other parts of the country, and the cross-sectional nature of the survey does not allow for inferences regarding causality. Self-reported response from the mothers is another limitation of this study, though probing questions were asked during interview and mothers had been invited to provide documents (for example birth certificate, antenatal care card, and others) to reduce the recall bias. Nonetheless, the strength of this study includes the objective assessment of the weight of the children and objective observations of some environmental factors during data collection.

\section{CONCLUSION}

Underweight among under-five children was significantly associated with the age of a child, purified water consumption practices, growth monitoring practices, and the mother's perception of small size at birth. These findings suggest the need for broader and longer-term interventions focusing on maternal and child nutrition promotion to reduce underweight among under-five children.

\section{AVAILABILITY OF DATA AND MATERIAL}

The data and findings related to this research are included in the manuscript.

\section{AUTHORS' INFORMATION}

DA holds an MPH and public health officer at the Ministry of Health Nepal. RK is a PhD candidate at The University Queensland School of Public Health, Australia. YP holds an MPH and is a Research Manager Nepal Health Sector Support Programme, Nepal. AP holds a PhD and is Associate Professor of Biostatistics at Tribhuvan University, Institute of Medicine, Department of Community Medicine and Public Health, Nepal.

\section{AUTHOR CONTRIBUTIONS}

DA designed the study concept and conducted statistical analysis of the manuscript. RK and YP contributed to data analysis, literature review, drafting and finalizing the manuscript. AP supervised the project. All the authors have read and approved the final version.

\section{ACKNOWLEDGMENTS}

The authors would like to acknowledge the Department of Community Medicine and Public Health (DCMPH), Institute of Medicine, Tribhuvan University and all the participants who participated in this study. We are very thankful to Professor Jane Heyworth and Dr. Julie Saunders of The University of Western Australia for their comments on the manuscript during revision. 


\section{REFERENCES}

1. Ezzati M, Lopez AD, Rodgers A, Vander Hoorn S, Murray CJ; Comparative Risk Assessment Collaborating Group. Selected major risk factors and global and regional burden of disease. Lancet (2002) 360(9343):1347-60. doi:10.1016/S0140-6736(02)11403-6

2. Black RE, Allen LH, Bhutta ZA, Caulfield LE, de Onis M, Ezzati M, et al. Maternal and child undernutrition: global and regional exposures and health consequences. Lancet (2008) 371(9608):243-60. doi:10.1016/ S0140-6736(07)61690-0

3. Sheeran J. The challenge of hunger. Lancet (2008) 371(9608):180-1. doi:10.1016/S0140-6736(07)61870-4

4. Horton R. Maternal and child undernutrition: an urgent opportunity. Lancet (2008) 371(9608):179. doi:10.1016/S0140-6736(07)61869-8

5. National Planning Commission. Multi-sector Nutrition Plan: For Accelerating the Reduction of Maternal and Child under-Nutrition in Nepal (2013-2017) (2012).

6. Victora CG, Adair L, Fall C, Hallal PC, Martorell R, Richter L, et al. Maternal and child undernutrition: consequences for adult health and human capital. Lancet (2008) 371(9609):340-57. doi:10.1016/S0140-6736(07)61692-4

7. Ministry of Health and Population. Nepal Health Sector Programme Implementation Plan II (NHSP -IP 2) 2010 - 2015. Kathmandu: Ministry of Health and Population (2010). 142 p.

8. Ministry of Health and Population (MOHP) [Nepal], New ERA, and ICF International Inc. Nepal Demographic and Health Survey 2011. Kathmandu, Nepal; Calverton, Maryland: Ministry of Health and Population, New ERA; ICF International (2012).

9. Ministry of Health, Nepal; New ERA; and ICF. Nepal Demographic and Health Survey 2016: Key Indicators. Kathmandu, Nepal: Ministry of Health, Nepal (2017).

10. Black RE, Victora CG, Walker SP, Bhutta ZA, Christian P, de Onis M, et al. Maternal and child undernutrition and overweight in low-income and middle-income countries. Lancet (2013) 382(9890):427-51. doi:10.1016/ S0140-6736(13)60937-X

11. Janevic T, Petrovic O, Bjelic I, Kubera A. Risk factors for childhood malnutrition in Roma settlements in Serbia. BMC Pub Health (2010) 10(1):509. doi:10.1186/1471-2458-10-509

12. Ministry of Health and A.M.I.I. New ERA, Nepal Demographic and Health Survey 2011. Calverton, Maryland: Ministry of Health and A.M.I.I (2012).

13. Gurung CK, Sapkota VP. Prevalence and predictors of underweight, stunting and wasting in under-five children. JNepal Health Res Coun (2009) 7(15):120-6.

14. Pramod Singh GC, Nair M, Grubesic RB, Connell FA. Factors associated with underweight and stunting among children in rural Terai of Eastern Nepal. Asia Pac J Pub Health (2009) 21(2):144-52. doi:10.1177/1010539509332063

15. Gakidou E, Oza S, Vidal Fuertes C, Li AY, Lee DK, Sousa A, et al. Improving child survival through environmental and nutritional interventions: the importance of targeting interventions toward the poor. JAMA (2007) 298(16):1876-87. doi:10.1001/jama.298.16.1876

16. Subba SH, Chandrashekhar TS, Binu VS, Joshi HS, Rana MS, Dixit SB. Infant feeding practices of mothers in an urban area in Nepal. Kathmandu Univ Med $J(2007)$ 5(1):42-9.

17. Martorell R, Leslie J, Moock PR. Characteristics and determinants of child nutritional status in Nepal. Am J Clin Nutr (1984) 39(1):74-86.

18. Subedi N, Paudel S, Rana T, Poudyal AK. Infant and young child feeding practices in Chepang communities. J Nepal Health Res Coun (2012) 10(21): 141-6.

19. Morrison J, Basnet M, Budhathoki B, Adhikari D, Tumbahangphe K, Manandhar D, et al. Disabled women's maternal and newborn health care in rural Nepal: a qualitative study. Midwifery (2014) 30(11):1132-9. doi:10.1016/j. midw.2014.03.012

20. Joshi SR, editor. District and VDC Profile of Nepal: A Socio-Economic Database of Nepal. Kathmandu: Intensive Study and Research Centre (2010).

21. W.H.O.M.G.R.S Group. WHO child growth standards based on length/height, weight and age. Acta Paediatr (2006) 450:76. doi:10.1080/08035320500495548

22. Ministry of Health and Population (MOHP) [Nepal], New ERA, and ICF International Inc. Nepal Demographic Health Survey 2006. Kathmandu, Nepal; Calverton, Maryland: Ministry of Health and Population, New ERA, and ICF International (2007).
23. Amano S, Shrestha BP, Chaube SS, Higuchi M, Manandhar DS, Osrin D, et al. Effectiveness of female community health volunteers in the detection and management of low-birth-weight in Nepal. Rural Remote Health (2014) 14(1):2508.

24. Lauritsen J, Bruus M. EpiData (version 3). A Comprehensive Tool for Validated Entry and Documentation of Data Odense. EpiData Association (2003).

25. Frost MB, Forste R, Haas DW. Maternal education and child nutritional status in Bolivia: finding the links. Soc Sci Med (2005) 60(2):395-407. doi:10.1016/j. socscimed.2004.05.010

26. Khatri RB, Mishra SR, Khanal V, Choulagai B. Factors associated with underweight among children of former-Kamaiyas in Nepal. Front Public Health (2015):3. doi:10.3389/fpubh.2015.00011

27. Acharya $P, K$ Kanal V. The effect of mother-educational status on early initiation of breastfeeding: further analysis of three consecutive Nepal Demographic and Health Surveys. BMC Public Health (2015) 15(1):1069. doi:10.1186/ s12889-015-2405-y

28. Khanal V, Sauer K, Zhao Y. Determinants of complementary feeding practices among Nepalese children aged 6-23 months: findings from demographic and health survey 2011. BMC Pediatr (2013) 13(1):1-13. doi:10.1186/1471-2431-13-131

29. Joshi N, Agho KE, Dibley MJ, Senarath U, Tiwari K. Determinants of inappropriate complementary feeding practices in young children in Nepal: secondary data analysis of Demographic and Health Survey 2006. Matern Child Nutr (2012) 8:45-59. doi:10.1111/j.1740-8709.2011. 00384.x

30. Aryal B. State of food (in) security in Chepang community: a case of Dahakhani VDC, Chitwan. Econ Lit (2016) 11:60-6. doi:10.3126/el.v11i0.14868

31. Mullany BC, Becker S, Hindin MJ. The impact of including husbands in antenatal health education services on maternal health practices in urban Nepal: results from a randomized controlled trial. Health Educ Res (2007) 22(2):166-76. doi:10.1093/her/cyl060

32. Phengxay M, Ali M, Yagyu F, Soulivanh P, Kuroiwa C, Ushijima H. Risk factors for protein-energy malnutrition in children under 5 years: study from Luangprabang province, Laos. Pediatr Int (2007) 49(2):260-5. doi:10.1111/j.1442-200X.2007.02354.x

33. Nakahara S, Poudel KC, Lopchan M, Ichikawa M, Poudel-Tandukar K, Jimba M, et al. Availability of childcare support and nutritional status of children of non-working and working mothers in urban Nepal. Am J Hum Biol (2006) 18(2):169-81. doi:10.1002/ajhb.20481

34. Fewtrell L, Kaufmann RB, Kay D, Enanoria W, Haller L, Colford JM Jr. Water, sanitation, and hygiene interventions to reduce diarrhoea in less developed countries: a systematic review and meta-analysis. Lancet Infect Dis (2005) 5(1):42-52. doi:10.1016/S1473-3099(04)01253-8

35. Jones AD, Cruz Agudo Y, Galway L, Bentley J, Pinstrup-Andersen P. Heavy agricultural workloads and low crop diversity are strong barriers to improving child feeding practices in the Bolivian Andes. Soc Sci Med (2012) 75(9):1673-84. doi:10.1016/j.socscimed.2012.06.025

36. Hackett M, Melgar-Quiñonez H, Álvarez MC. Household food insecurity associated with stunting and underweight among preschool children in Antioquia, Colombia. Revista Panamericana de Salud Pública (2009) 25(6):506-10. doi:10.1590/S1020-49892009000600006

37. Pradhan A. Factors associated with nutritional status of the under five children. Asian J Med Sci (2014) 1(1):6-8.

38. Kirchengast S, Hartmann B. Maternal prepregnancy weight status and pregnancy weight gain as major determinants for newborn weight and size. Ann Hum Biol (1998) 25(1):17-28. doi:10.1080/03014469800005402

39. Christian P, Khatry SK, Katz J, Pradhan EK, LeClerq SC, Shrestha SR, et al. Effects of alternative maternal micronutrient supplements on low birth weight in rural Nepal: double blind randomised community trial. BMJ (2003) 326(7389):571. doi:10.1136/bmj.326.7389.571

40. Acharya PP, Alpass F. Birth outcomes across ethnic groups of women in Nepal. Health Care Women Int (2004) 25(1):40-54. doi:10.1080/07399330490253210

41. Sharma SR, Giri S, Timalsina U, Bhandari SS, Basyal B, Wagle K, et al. Low birth weight at term and its determinants in a tertiary hospital of Nepal: a case-control study. PLoS One (2015) 10(4):e0123962. doi:10.1371/journal.pone. 0123962

42. Bhandari N, Mazumder S, Bahl R, Martines J, Black RE, Bhan MK, et al. An educational intervention to promote appropriate complementary feeding 
practices and physical growth in infants and young children in rural Haryana, India. J Nutr (2004) 134(9):2342-8.

43. Ashworth A, Shrimpton R, Jamil K. Growth monitoring and promotion: review of evidence of impact. Mater Child Nutr (2008) 4:86-117. doi:10.1111/j.1740-8709.2007.00125.x

44. Ministry of Health and Population. Annual Report. 2012/13. Nepal: Ministry of Health and Population (2013).

45. United States Agency for International Development, Global Health Technical Assistance Project. Food Utilization Practices, Beliefs and Taboos in Nepal an Overview. Kathmandu, Nepal: United States Agency for International Development, Global Health Technical Assistance Project (2010).

46. Singh A, Klemm RD, Mundy G, Pandey Rana P, Pun B, Cunningham K. Improving maternal, infant and young child nutrition in Nepal via peer mobilization. Public Health Nutr (2017) 1-11. doi:10.1017/S1368980017002993
47. Simkhada B, van Teijlingen ER, Porter MA. The role of mothers-in-law in antenatal care decision-making in Nepal: a qualitative study. BMC Pregnancy Childbirth (2010) 10(1):34. doi:10.1186/1471-2393-10-34

Conflict of Interest Statement: The authors declare that the research was conducted in the absence of any commercial or financial relationships that could be construed as a potential conflict of interest.

Copyright (C) 2017 Adhikari, Khatri, Paudel and Poudyal. This is an open-access article distributed under the terms of the Creative Commons Attribution License (CC $B Y)$. The use, distribution or reproduction in other forums is permitted, provided the original author(s) or licensor are credited and that the original publication in this journal is cited, in accordance with accepted academic practice. No use, distribution or reproduction is permitted which does not comply with these terms. 